\title{
User Preferences on Cloud Computing and Open Innovation: A Case Study for University Employees in Greece
}

\author{
Eleni C. Gkika ${ }^{1}$, Theodoros Anagnostopoulos ${ }^{1,2} \mathbb{D}$, Stamatios $\mathrm{Ntanos}^{1, * \mathbb{C}}$ and \\ Grigorios L. Kyriakopoulos 3,*(D) \\ 1 Department of Business Administration, University of West Attica, 12244 Athens, Greece; \\ ghelena@uniwa.gr (E.C.G.); thanag@uniwa.gr (T.A.) \\ 2 Department of Infocommunication Technologies, ITMO University, 197101 Saint Petersburg, Russia \\ 3 Photometry Laboratory, Electric Power Division, School of Electrical and Computer Engineering, National \\ Technical University of Athens, 9 Heroon Polytechniou Street, 15780 Athens, Greece \\ * Correspondence: sdanos@uniwa.gr (S.N.); gregkyr@chemeng.ntua.gr (G.L.K.)
}

Received: 30 March 2020; Accepted: 8 June 2020; Published: 9 June 2020

\begin{abstract}
Cloud computing hastens technology driven innovation by taking advantage of the speed, the cost-effectiveness, the efficiency and the security that such applications offer. By using cloud computing, public organizations can exploit the economies of scale and innovate both efficiency and rapidly. The present study focuses on the factors influencing the adoption of a new technological application within the procedures of change management. It examines the willingness to adopt cloud computing for the case of administrative employees in a higher education institute working environment. A prediction model explores a Ubiquitous cloud computing adoption system (USAS), utilizing the theory of technology acceptance model (TAM) and resulting that end users are welcoming the adoption of the cloud computing. Policy makers should move towards empowering the stakeholders with e-skills to stimulate technology driven innovation, resulting in improvements in effectiveness and efficiency, in the creation of new jobs and in the promotion of sustainable development practices.
\end{abstract}

Keywords: technology acceptance model; technology driven innovation; cloud computing; support vector machine; SVM classifier; open innovation

\section{Introduction}

One of the recently emerged technological evolutions is cloud computing. It allows for organizations to have access to computing resources hosted by third parties through the Internet or Web servers (the 'cloud') [1] and benefit instead of building or expanding their own IT infrastructures. cloud computing offers organizations the opportunity to adopt information technologies (ITs) that could not otherwise afford due to high cost [2]. It also allows for accessibility to data, quick processing, easy transfer and storage of digital resources regardless of location, time, borders and geographical distances $[3,4]$. cloud computing services emphasize on providing low cost or free applications through the Internet.

To date, research mostly focused on the adoption of cloud computing by organizations through the technology-organization-environment (TOE) model, by studying the underlying factors of the organizational settings [5-7]. Very few studies have explored the factors that influence the adoption of cloud computing by specifically concentrating on the end users $[2,7,8]$. The end users are approaching cloud computing as professionals/ employees or individually for private use. Sharma, et al. [2] and Yang, et al. [9] have examined the employee's perceptions of using cloud computing at a public sector working 
environment. This subject requires attention since users' perceptions may influence and motivate the implementation of cloud computing in an organization. The adoption procedure of cloud computing may fail if end users within the organization resist to or sabotage the adoption of this new technology. To understand the factors that influence end user's adoption, the methodology of technology acceptance model (TAM) is used. TAM explains user's intention to use the technology [10-12].

Through the TAM model, Davis [11] applies the constructs of perceived ease of use (PEOU) and perceived usefulness (PU) as beliefs capable to predict future behavior of the users. Some researchers propose the extension of this research model by adding more variables that may influence users' behavioral intention to adopt the cloud computing [2]. In addition, information system researchers have proposed the use of predictive analytics instead of explanatory statistical analysis to build and test the theory [13-15].

Public sector globally has delayed in adopting cloud computing compared to the private sector. Some of the hurdles that public sector organizations incur is the lack of in-house expertise on Information Technologies (ITs), the lack of trust in the technology or the providers, the absence until recently of regulatory authorities and the lack of willingness to change the currently used procedures $[16,17]$. The cloud computing situation in EU-28 is illustrated in Figure 1, according to Eurostat data [18]. This figure shows a rising trend in cloud computing usage between 2014-2018 for all countries. Nowadays, almost one out of four enterprises in Europe (with Internet access and $>10$ employees) uses cloud computing. Greece falls back in cloud services diffusion, where only $13 \%$ of the surveyed companies used cloud computing. One of the prevailing characteristics of Greek economy is that it consists of a business network where $95 \%$ of businesses are small and medium-sized enterprises (SMEs) that have less than 10 employees, so authors assumed that these enterprises were not surveyed [19].

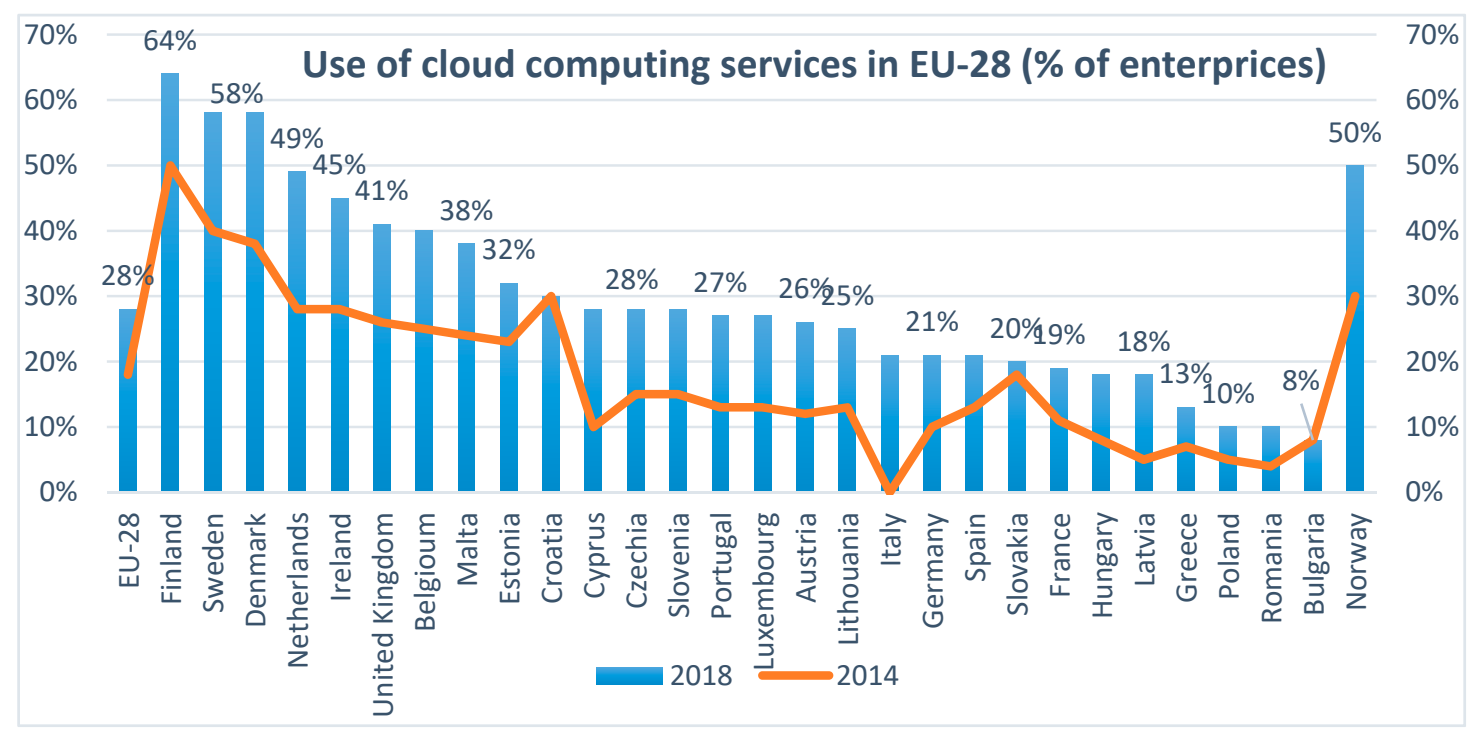

Figure 1. Cloud computing Usage in EU-28 enterprises (created by the authors according to Eurostat [18]).

The economic crisis and the problems caused in the global financial system affected, among others, the operations of educational establishments, with governments spending less money than before to invest in upgrading them [20]. The rapid development of technology demands continuous upgrades on hardware and software programs and creates pressure to educational institution budgets to keep up with digital technologies. cloud computing seems to be the opportunity for the educational system to invest on the new way of delivering computing services and benefit from the flexibility of "paying as you go" cost structure. Furthermore, strategic alliances between private firms and education institutes under the concept of open innovation offer significant benefits for all parties involved. One of the main characteristics of cloud computing are the significant cost advantages on IT expenditures and 
the simplification and convenience of the way computer related services are delivered, since cloud computing services can be accessed by less powerful devices, such as smartphones or notebooks [21,22]. Document sharing and editing at the same time by different employees (for example via Office 365 platform) enhances elaboration and efficiency of administrative staff [22]. cloud computing permits the reduction in administrative overheads and reduced resource management costs [23]. The research of the Washington State University's School of Electrical Engineering and Computer Science (EECS) concluded that despite the challenging economic climate, cloud computing has led to an expansion of the services offered to staff and students [24].

This research analyzed the adoption process of cloud computing by end users and identified the factors affecting their adoption decision, by using the case of administrative personnel working at two public universities in Greece. The contribution of this study is significant for implications on public economic organizations due to the difficult economic conditions that Greece has faced during the last decade and which do not allow for high-cost investments to implement technologies that can be challenged by end users. Furthermore, the collected data are analyzed through classification algorithms to predict the cloud technology use intention and the best method is identified. More specifically, the research model and the hypotheses are looking for the factors to determine any significant impact on the administrative personnel's behavioral intention to adopt cloud computing.

The remainder of the study is structured as follows: A literature review provides the background on cloud computing and models of adoption theory; then the foundations theory of the research model are presented and the research hypotheses are proposed. After the results, the main findings and their implications are outlined in a discussion and conclusion section about the empirical results. The final section also includes limitations for future research.

\section{Literature Review}

\subsection{Cloud Computing and Open Innovation}

The concept of open innovation promotes the idea that knowledge is better developed both inside the limits of an organization and outside of it. The concept of open innovation supports the sharing of a firms' unused resources with other organizations, the common collaboration of resources and the formation of alliances. Open innovation offers significant benefits such as cost reduction, access to new ideas and more funding research and development (R\&D) capabilities [25]. A close relation of the adoption of open innovation and a firm's performance was reported for the case of an information and communication company [26]. One of the novel operations that emerged during the last decade within information and communication technologies is cloud computing [27]. The term describes a model that enables ubiquitous, convenient on demand network access to computing resources, rapidly provisioned and released with minimal management efforts [28]. There are software applications that are available to users via high speed Internet access and consist of two components, infrastructure of the cloud and software applications that run on the cloud. The first component consists of the hardware resources required to support the cloud services that are provided as server, storage and network components. The second component refers to software applications and computing power for running business applications, as provided via the Internet by third parties. Large-scale enterprises, SMEs and public organizations seek the advantages that cloud computing offers; reduced cost of IT services, minimum infrastructure investments, increased reliability, availability and flexibility of services [7]. There are four different models that an organization may choose for cloud computing: (a) The public cloud, which is available through a third-party service provider, e.g., Google Apps, (b) The private cloud, which is managed within the organization or a large company in a segregated area (physically and logically), (c) The Community cloud, which is used and controlled by a group of companies who share common interests and (d) The Hybrid cloud, which is a combination of public and private cloud [22]. 
The applications provided in cloud computing include: (a) software as service (SaaS) applications such as word processing, CRM (customer relationship management), ERP (enterprise resource planning) which are available over the Internet (hosted) from commercial vendors such as Gmail, Google Apps, Facebook, Cisco WebEx, (b) platform as service (PaaS) applications, which are platforms and software development kits available over the Internet from commercial vendors such as Microsoft Azure services, Google App platform, Amazon relational database, (c) Infrastructure as service (IaaS) applications, which are tangible physical devices like virtual computer servers, storage devices that are located in a data center and can be assessed and used over the Internet using login authenticating system and passwords [22]. For example, in an educational institution, administrative personnel, academic staff and students can use the service of SaaS and IaaS applications of cloud computing providers. Any software launched by end users resides at the server of the SaaS cloud provider and is assessed online [20]. The same SaaS applications addressed to medium sized e-commerce business having criteria as complexity, reliability, security, privacy, firm size while a business should choose PaaS or IaaS applications with criteria of compatibility and scalability [29].

Among the benefits of cloud computing are the scalability, the ease of implementation and enhanced service quality provided to users. Poniszewska-Maranda et al. [30] examined the combination of real time systems and the use of cloud computing and resulted in building efficient systems.

Adopting cloud computing, may also imply organizational risks related to data protection of organizations, businesses and citizens, data confidentiality, data integrity and general security concerns. There is a fear of data segregation in the cloud and worries about the long-term viability of the cloud computing provider [31]. Other risks include disputes or litigation with the provider about service debasement, cost escalation or hidden service costs and fear of data segregation in the cloud [32].

The use of cloud computing services in higher education institutes can set an example and promote the development of the organization [25]. The alliances between government, universities and businesses (known as triple helix) concerning the promotion of R\&D and open innovation concept is emphasized in a review study concerning the public support for open innovation [33]. It is mentioned that "public investment in education, mainly at a postgraduate level, can promote regional and national innovation systems" [33].

European Union (EU) has acted towards the protection of citizens, civil servants and economic entities by introducing the EU's general data protection regulation [34]. Some EU countries have developed their own guidelines on cloud computing services. In Greece a local implementation law at 2019, along with EU's general data protection regulation [34], underlines critical issues about insuring data security and data protection with reference to legal and operating issues, including the obligation of cloud providers to provide transparency in collecting and processing personal data relating to customers, provide security and decryption of data and prevent transfer of these data to third parties [34].

Next, authors discuss the factors that may influence the end users' adoption of cloud computing in a working environment and authors made the hypotheses for this research study.

\subsection{User Adoption of Cloud Computing}

Exploring technology acceptance by end users is a longstanding issue in management information systems (MIS) research. Performance gains from the adoption of a new technology may be delayed or postponed if users are unwilling to accept and use the available systems/applications [35].

The successful implementation and adoption of a new technology such as cloud computing depends on technical factors of IT, on characteristics of the organization that introduces the technology and on the response of professionals/employees within the organization, the end users of the new technology [36].

Prevailing models in explaining technology adoption by end users is the technology acceptance model (TAM) Davis [37], the theory of reasoned action (TRA) [38] and the theory of planned behavior (TPB) [39]. The models of TRA and TPB predict the factors that influence the users' intention to use a 
new technology. According to TRA, someone's intention is a direct determinant of his future attitude. Attitude and subjective norms (the opinion of important others) influence users' intention to perform towards the new technology. The TAM aims at tracing the impact of external factors on internal beliefs of the end user and their attitudes.

TAM was extensively used in a wide range of scientific domains such as: e-learning [40,41], Internet banking [12,42-44], mobile learning [45-48] and social networking [37,49].

According to TAM [50] there are two perceptions in adopting a new technology: the perceived usefulness (PU) of the new technology and the perceived ease of use (PEOU). These internal beliefs according to TAM determines the behavioral intention and the attitude of the user to perform towards the adoption of the new technology. These beliefs mediate the influence of all other factors in the acceptance and usage of new information systems [51].

Davis [11] stated that the belief of perceived usefulness (PU), is someone's belief that a system is "capable of being used advantageously" p. 320 [11]. Another definition of perceived usefulness is "the degree to which an individual believes that using a particular system would enhance his or her job performance". Potential users could consider a specific technology as useful, but at the same time they could consider it as hard to learn and use, thus questioning the performance benefits resulting from the usage. Hence, in addition to the usefulness, usage is influenced by application's perceived ease of use. If a system fails to support people in performing better in their jobs then the new technology is not likely to be accepted, despite of careful implementation efforts by the management [52].

Perceived ease of use (PEOU) refers to someone's belief that using a new technology would be free of physical or mental effort or any kind of difficulty. PEOU is supported to have a significant direct effect on perceived usefulness (PU) of the new technology [53]. Some studies in Information systems adoption literature including new technologies refer to the influence of PEOU on the technology acceptance. These subjects are on internet banking [12], smartphone technologies [54] and mobile internet $[2,55]$.

PU is considered a significant factor in predicting technology adoption. Kryvinska et al. [2] and Chong [13] support the hypothesis that PU plays a significant role in the adoption of Internet services. Almazroi et al. [56] examined factors influencing the adoption of cloud computing and resulted that perceived usefulness was the strongest predictor of users' behavioral intention. There are studies that resulted that PEOU is a much stronger predictor for adoption than the PU [36]. A study by Chong [13] used advanced hybrid statistical modeling and found that ease of use was not a statistically significant predictor [2].

Various studies researched the existence of psychological factors and individual differences as contributors to forming perceptions towards the adoption of cloud computing [57]. Venkatesh and Davis [53] and Venkatesh [58] researched the model TAM2 which incorporates additional external variables as factors influencing the adoption of the new technology [59]. According to TAM2, a person's performance is determined by his behavioral intentions. Behavioral intention is the potency of one's intention to perform a specific behavior and is determined by ones' Attitude and by his Subjective norms. A negative attitude during technology's initial implementation forms perceptions affecting the intrinsic motivation to adopt the technology [60]. Gupta in a research on SME's adoption of cloud computing concluded that PEOU and convenience were the strongest predictors of adoption [22]. Gangwar and Date [61] resulted that threat, risk, vulnerability, availability, support and compliance are important determinants in adoption of cloud computing in Indian organizations [57]. Behrend et al. [36], examined the factors affecting the adoption of cloud computing in colleges. They searched additional determinants to PEOU and PU in an extended version of TAM (TAM 3) [62]. They resulted that important determinants of PEOU are individual differences, such as information technology self-efficacy and computer anxiety-and some facilitating conditions such as trust. The social influence is an important determinant of PU that affects the behavior of the user and the specific system characteristics [36]. 
Information technology self-efficacy and computer anxiety are two factors that have impact on user's behavior. The perception of Ease of use influences peoples' attitude and their behavior through self-efficacy. According to Bandura [63] self-efficacy is a judgement of how well someone can execute actions required in order to deal with prospective situations. According to Compeau and Higgins [64] computer self-efficacy is the degree that an individual believes that is capable to perform a specific task or job using a computer or a related technology. information technology self-efficacy is an important factor to consider when determining whether administrative personnel will adopt cloud computing [28]. Ashtari and Eydgahi [28], found that information technology self-efficacy was a strong and significant predictor of users' perceived usefulness of cloud computing applications. Sharma et al. [2] resulted that information technology self-efficacy, trust and job opportunity are important predictors of adoption of cloud computing. Having higher degree of information technology self-efficacy is expected to influence users to feel more comfortable in learning new knowledge for Internet activities and helps them achieve the desired results [2].

Information technology anxiety is defined by Venkatesh [58] as an individual's discomfort in the possibility of using computers. Computer anxiety refers to negative emotions, fear or anxiety towards computer usage and hostile or aggressive thoughts about utilization of computer-based technology [28,65]. Ashtari and Eydgahi [28] resulted in significant negative correlations in information technology anxiety and PU of cloud computing.

One of the main concerns in cloud computing adoption remains the systems' security and unauthorized access and loss due to breaches of security [28]. In addition, Liao and Cheung [66] found that system security is a significant determinant of user's adoption. The risk minimizes as authentication and encryption procedures are applied to data [22]. Users' intention to adopt cloud computing follows the trust to the system provider, to minimize the risk of system failure or the fear to experience personal loss of money, time or data [67]. Ma et al. [68] resulted that potential users tend to adopt cloud computing services based on the trustworthiness of service provider. It was also emphasized that adopters continue to use CC if their quality of experience is as per their expectation. A zero difference between user's prior expectations and the actual perceived performance of the technology enhance adoption [69].

Data privacy risks are among the first issues reported by users of cloud computing [70]. In order to protect citizens, businesses and some governments in European Union (EU) along with EU's GDRP regulations have also enact privacy regulations that aim at providing increased levels of security for citizens and prohibit the leakage of sensitive personal data outside the EU. These regulations prompted Amazon among others to expand on storage facilities located within EU [34].

\section{Materials and Methods}

In the current research authors pertain the adoption of cloud computing through the prism of individual user choice adoption, while the innovation diffusion and adoption studies in technological and organizational context are approached through the diffusion of innovation theory (DOI) [71] and the technology, organization and environment framework (TOE) [5]. The research model that guided the study measured perceived usefulness and perceived ease of use by using items adopted from studies on technology adoption theory, the TAM2 instrument $[53,58]$. The items for self-efficacy were adopted from [64,72]. The items of perceived risk were based on [73]. The proposed model aims to predict cognitive and affective determinants of cloud computing adoption by end users.

\subsection{Data Collection}

To determine user's intention to adopt cloud computing, a survey was conducted during the second quarter of 2019. Initially, a pilot study was performed to 30 participants to ensure the applicability of the construct. Questionnaires were afterwards distributed to 820 administrative personnel of two Greek public universities resided in the largest city of Greece, Athens, the University of West Attica and the Panteion University, in a method of convenience sampling. The total number 
of Administrative personnel working at 36 Greek universities is 7751 persons, according to the Education and Lifelong Learning Center of University of Athens. Participants were administrative employees, familiar with Internet access for inquiries and communication purposes with other people or organizations. Participation was voluntary. All respondents were assured for privacy and were asked to indicate the extent of their agreement with the statements of the questionnaire. All questionnaires were distributed and recollected after one week. A total of 702 complete responses were obtained, with a response rate of $86 \%$. Finally, 697 usable questionnaires were collected after eliminating incomplete questionnaires (net response rate of $85 \%$ ). Demographic variables such as gender, age, education, job position and work experience were adopted from [74] and were employed to estimate possible response bias.

\subsection{Experimental Setup Dataset Structuring}

Authors evaluated the given dataset where each instance summarizes data collected for a certain user. The dataset was created by collecting variables concerning user's preferences with regards to cloud computing adoption at the public sector working place. Our class attribute (dependent variable) is a binary question (no/yes) concerning users' preference to adopt cloud-computing technology soon. Specifically, the research questionnaire contained of 23 questions on the opinion of each user separately. The dataset structure is presented in Table 1.

Table 1. Dataset Structure.

\begin{tabular}{ccc}
\hline Attribute & Type & Value \\
\hline Adoption & Predictive & $\{0,1,2,3,4\}$ \\
Use & Predictive & $\{0,1,2,3,4\}$ \\
Satisfaction & Predictive & $\{0,1,2,3,4\}$ \\
Job performance & Predictive & $\{0,1,2,3,4\}$ \\
Work more quickly & Predictive & $\{0,1,2,3,4\}$ \\
Increase productivity & Predictive & $\{0,1,2\}$ \\
Make job easier & Predictive & $\{0,1,2\}$ \\
Effectiveness & Predictive & $\{0,1,2\}$ \\
Perceived information quality & Predictive & $\{0,1,2\}$ \\
Perceived system quality & Predictive & $\{0,1,2\}$ \\
Efficiency & Predictive & $\{0,1,2\}$ \\
Access costs & Predictive & $\{0,1,2\}$ \\
Ease to use & Predictive & $\{0,1,2,3,4\}$ \\
Ease to become skillful & Predictive & $\{0,1,2,3,4\}$ \\
Ease to learn & Predictive & $\{0,1,2,3,4\}$ \\
Predisposition & Predictive & $\{0,1\}$ \\
Security & Predictive & $\{0,1\}$ \\
Work experience & Predictive & $\{0,1\}$ \\
Education & Predictive & $\{0,1,2,3,4\}$ \\
Gender & Predictive & $\{0,1,2\}$ \\
Age & Predictive & $\{0,1\}$ \\
Preference to Adopt cloud computing & Predictive & $\{0,1,2,3\}$ \\
& Class & $\{\mathbf{0 , 1}\}$ \\
\hline
\end{tabular}

Out of the 702 users, the actual dataset had 697 instances because there were omitted instances with missing values. Each instance depicts all the available information of a unique user taking part to the survey. Hence, authors performed predictive analytics for the preference to adopt cloud-computing technology in the working environment with the data produced by 697 users participating in the incorporated survey. In addition, each instance of the dataset had 23 attributes, 22 of them where predictive attributes, while the last one is the class attribute. Since the class attribute (preference to adopt cloud-computing) takes only two values (no/yes), authors used binary classification algorithms. The initial value is 466 out of 697 users that were willing to adopt in 
cloud-computing soon. The 22 predictive attributes take categorical values in the range of "strongly disagree" to "strongly agree". The class attribute takes value either 0 or 1 , where 0 value means that the user is not ready to adopt cloud computing soon and 1 value means that the user is ready to adopt cloud computing.

\subsection{Adopted Classifiers}

Authors experimented with binary classifiers where it was assessed their efficiency to rank them and propose an optimal solution. Such solution enables the prediction of user preferences in the working environment regarding the adoption of cloud computing technology in the public sector [75-78]. Machine learning classification algorithms are used as the core object of performing predictive inference analytics. Such algorithms according to the predicted values of the examined model are divided in two major categories. In the first category the predicted value is numerical, which is in the case of regression analyses. Instead, in the second category the predicted value is categorical, which is in the case of classification analyses. If there are more than two classes, authors dealt with multiclass classification. In the specific case where the predicted categorical values take only two class values authors dealt with binary classification.

To define which classifiers to adopt in this study authors experimented with certain classification algorithms available in Weka [79]. Such classifiers are:(1) k-nearest neighbors, i.e., k-NN, (2) One R, (3) Hoeffding tree and (4) support vector machine, i.e., SVM. It was assessed the prediction accuracy of each selected classifier to rank them and define the optimal one for our problem.

The experimented parameters of the final dataset include the adopted classifiers, the evaluation method, as well as the evaluation metrics incorporated to assess the proposed classification models. See Table 2.

Table 2. Experimental setup parameters and values.

\begin{tabular}{cc}
\hline Parameter & Value \\
\hline 1st Experimented classifier & k-NN \\
2nd Experimented classifier & One R \\
3rd Experimented classifier & Hoeffding tree \\
4th Experimented classifier & SVM \\
Evaluation method & 10-fold cross-validation \\
Evaluation metrics & $a$, Confusion matrix \\
\hline
\end{tabular}

\subsection{Evaluation Method and Metrics}

Authors evaluated the examined models with 10-fold cross-validation evaluation method, which divides the initial dataset to 10 equal sized parts and then in certain loop incorporates the first 9 parts to train the classifier and the remaining 1 to test the classifier. This process is repeated until all the parts are used for training and testing. To clarify the creation of the training and testing datasets the authors used 9 parts of the initial dataset in 10 certain loops, to create the training dataset. The remaining last part is used to create the testing dataset. By the end of the process, it holds that all the parts of the initial dataset have been used for the creation of certain training and testing datasets. The process prevents the use of a single part to belong both to training and testing dataset, thus once per part is used for the creation of the training dataset it is not allowed to form the testing dataset. The 10-fold cross-validation is a common evaluation method in machine learning literature to assess the efficiency of a classifier, especially when the available amount of data in the dataset is limited, as it is the case in our study.

It was also evaluated the adopted classification models with the confusion matrix evaluation metric. The confusion matrix is a special form of matrix, which in the case of binary classification has the following form, as described in Table 3: 
Table 3. Confusion matrix.

\begin{tabular}{ccc}
\hline Class 0 & Class 1 & $\leftarrow$ Classified as \\
\hline A & B & class 0 (not prefer cloud computing) \\
C & D & class 1 (prefer cloud computing) \\
\hline
\end{tabular}

Where, " $A$ " quantity depicts the number of class 0 instances, which are classified correct as instances of class 0 . "B" quantity depicts the number of class 0 instances, which are falsely classified as instances of class 1 . " $\mathrm{C}$ " quantity depicts the number of class 1 instances, which are classified falsely as class 0 instances, while " $\mathrm{D}$ " quantity depicts the number of class 1 instances correctly classified as instances of class 1 . A given classification model is considered as effective if it maximizes " $A$ " and " $D$ " quantities, while concretely minimizes " $B$ " and " $C$ " quantities.

Authors assessed the effectiveness of the adopted classifiers by incorporating the prediction accuracy evaluation metric, $a \in[0,1]$, which is defined in the following equation:

$$
a=\frac{t_{p}+t_{n}}{t_{p}+f_{p}+t_{n}+f_{n}}
$$

where, $t_{p}$, are the instances, which are classified correct as positives and $t_{n}$, are the instances, which are classified correct as negatives. In addition, $f_{p}$ are the instances, which are classified false are positives and $f_{n}$, are the instances, which are classified false as negatives. A low value of $a$ means a weak classifier while a high value of $a$ indicates an efficient classifier.

To equally treat the classifiers' performance we introduce the time required to build model, qualitative evaluation metric, $t \in(0$, infinity $)$. Given a certain dataset as input $t$, is able to qualitatively inform us regarding the classifier complexity and computation costs. The qualitatively rational behind $t$ evaluation metric is that the less complex and less computation costly the classifier is the less time to build model, $t$, is required. Specifically, a low value of $t$ indicates that the selected classifier is less complex and requires less computation costs than another classifier, which has a higher value of $t$. When the lower bound of $t$ is near to zero, this means that the classification model is efficient with regards to algorithm complexity and computation costs while if the upper bound is near to infinity, this means that the classifier is not optimal for the same input dataset.

\section{Results}

\subsection{Description}

Respondents' demographic profile showed that more than $83 \%$ of the respondents had university degree or higher degree while the years of their experience varied between "less than 5 years" for $45 \%$ of the respondents and "more than 10 years" for more than $40 \%$ of the respondents. Their working duties ranged widely between administration, management, planning, research and technical support. Generally, all respondents were familiar with the usage of Internet/www. According to Figure 2, most the respondents were female (62\%). Women prefer to be occupied at service sector providing support and services as they were characterized as "nurturing" [44].

Concerning the age of the respondents, according to Figure 3, more than $50 \%$ of the sample were between 30 to 50 years. Almost 7\% of the respondents were more than 51 years old. 


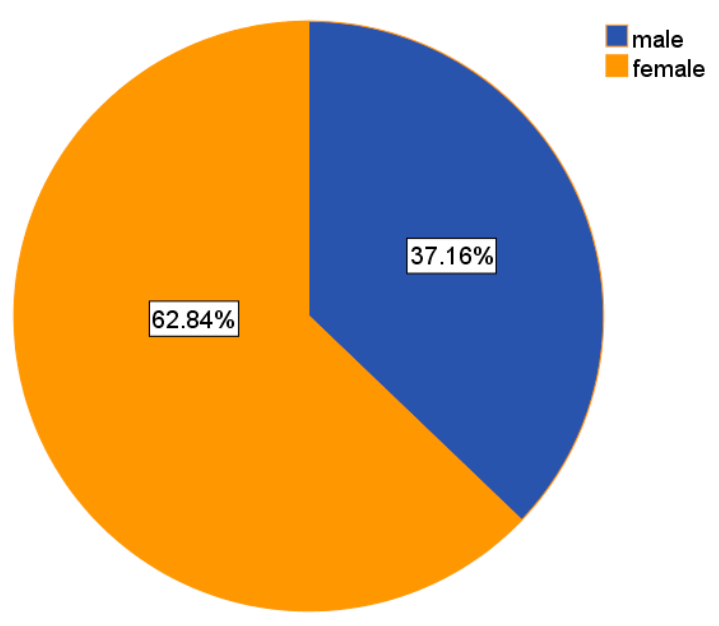

Figure 2. Gender distribution.

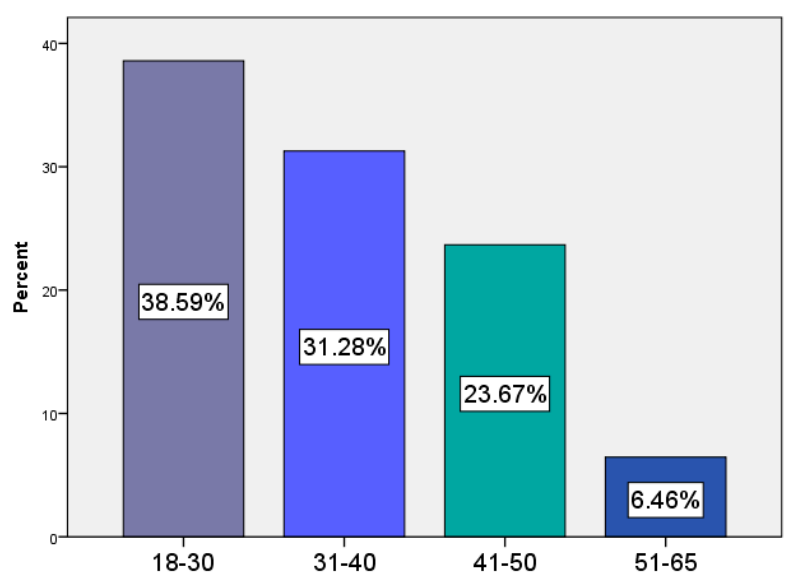

Figure 3. Age distribution.

According to Figure 4, the majority (82\%) of end users of cloud computing had acquired a university degree or had completed postgraduate studies.

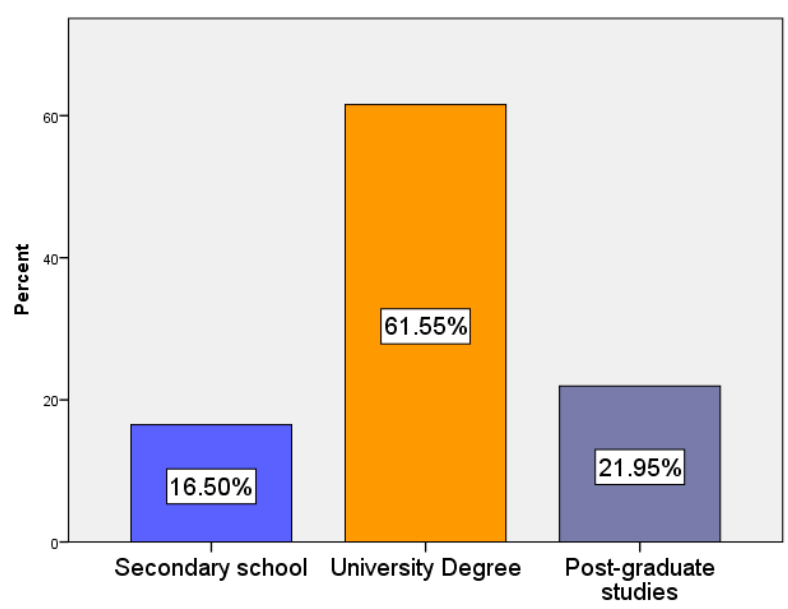

Figure 4. Education distribution.

Concerning work experience, according to Figure 5, more than half of the respondents had working experience below 10 years while $20 \%$ had an experience of more than 20 years. 


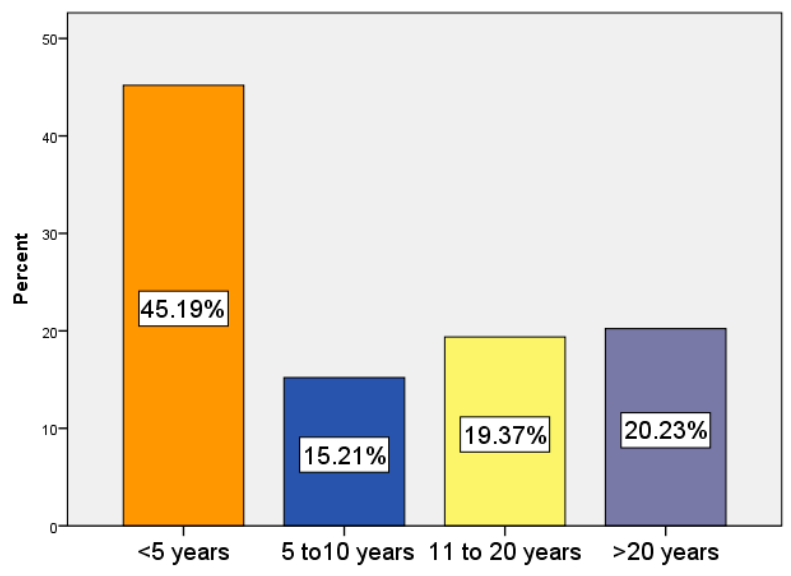

Figure 5. Work experience distribution.

The distribution of job position among end users ranged between $8 \%$ directors, $29 \%$ supervisors and $63 \%$ administrative personnel, as depicted in Figure 6.

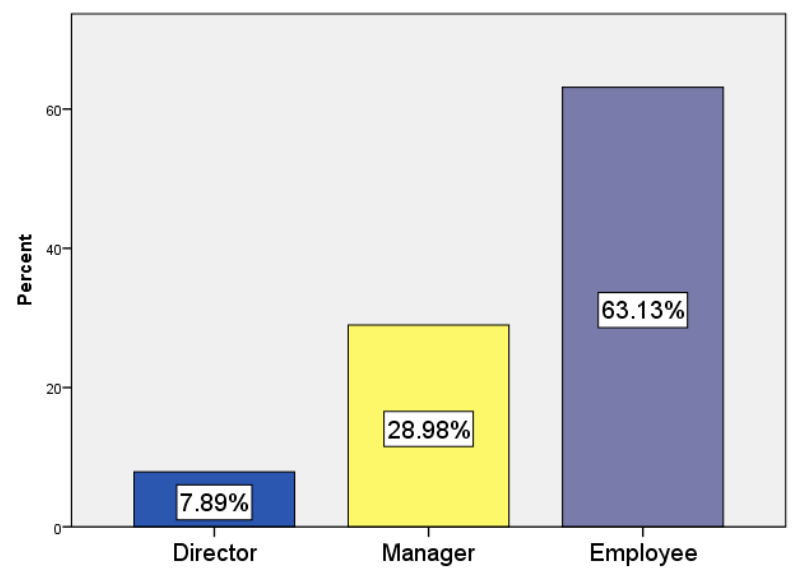

Figure 6. Job Position distribution.

According to descriptive analysis in Figure 7. respondents were familiar with cloud computing and were willing to adopt it in performing their work duties. They agreed that cloud computing was a technology "easy to use" and "easy to become skillful at using it". But respondents expressed their disagreement on the statements that "cloud computing helps them working more quickly" or that cloud computing was able to increase their "job performance" or that cloud computing may "increase their productivity" or "the effectiveness of their job". They did not consider that their "efficiency was affected by cloud computing usage" and that cloud computing could "make their job easier". Since our sample was of administrative personnel that were not currently using the cloud computing in the working environment, they were not in position to compare the results of using cloud computing or not. New technologies become more appealing to their results since users get familiar and gained experience in using them [80]. The opinions of respondents on cloud computing "perceived information quality" were vague. After implementing cloud computing, few organizations had to increase their bandwidth connection so that users were able to enjoy the benefits of cloud computing. These perceptions further influence respondents' levels of satisfaction in using cloud computing. Respondents also could not decide whether cloud computing "influences their access costs to Internet/web". Employees working in an organization enjoyed the benefit of free wi-fi Internet access, so they did not have an opinion about the cost of usage. 


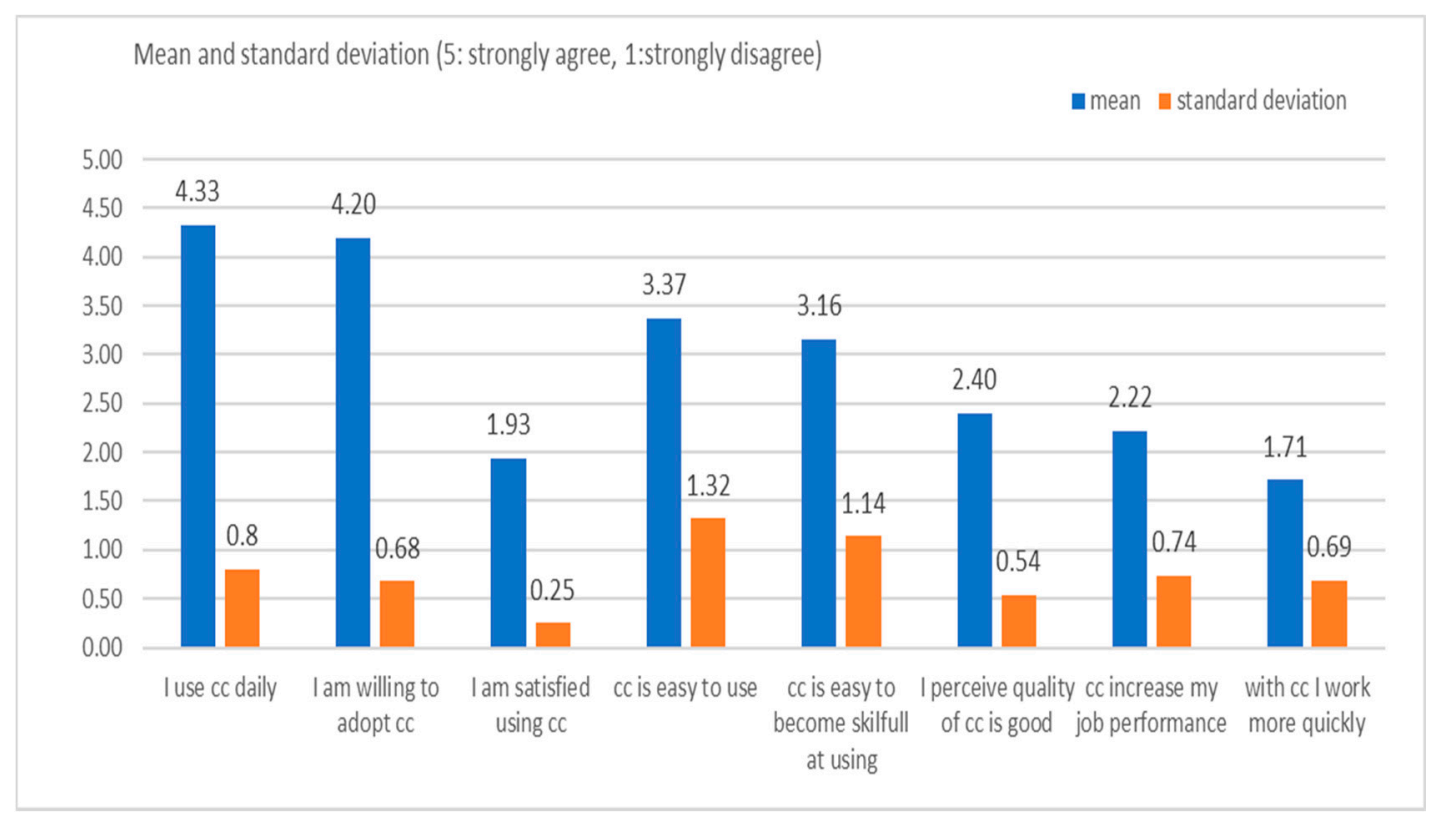

Figure 7. Cloud Computing (cc) adoption variables.

Respondents also could not decide whether cloud computing "influence their access costs to internet/web". Employees working in an organization enjoy the benefit of free wi-fi Internet access, so they do not have an opinion about the cost of usage.

When the dataset was created, it was used Weka open source software to examine which classifier to adopt for the prediction purpose in our case [79].

\subsection{Experimented Classifiers Prediction Accuracy}

Authors evaluated the classification algorithms of the proposed model for the final dataset. It was used 10-fold cross-validation applied to the dataset. For the selected classifiers authors obtained the following values of prediction accuracy: k-NN classifier achieves $a=0.8464$, One R classifier achieves $a=0.8895$, Hoeffding tree classifier achieves $a=0.9454$ and SVM classifier achieves $a=0.9985$, as depicted in Figure 8. It was observed that SVM classifier achieves the higher prediction. To adopt this classifier as the proposed classification model for the research problem authors applied McNemar's statistical significance test on the classification resulted of all the selected classifiers. McNemar's test proved that all the selected classifiers had statistically significant prediction accuracy results compared with SVM classifier's prediction accuracy. Therefore, authors adopted SVM classifier as the best prediction model.

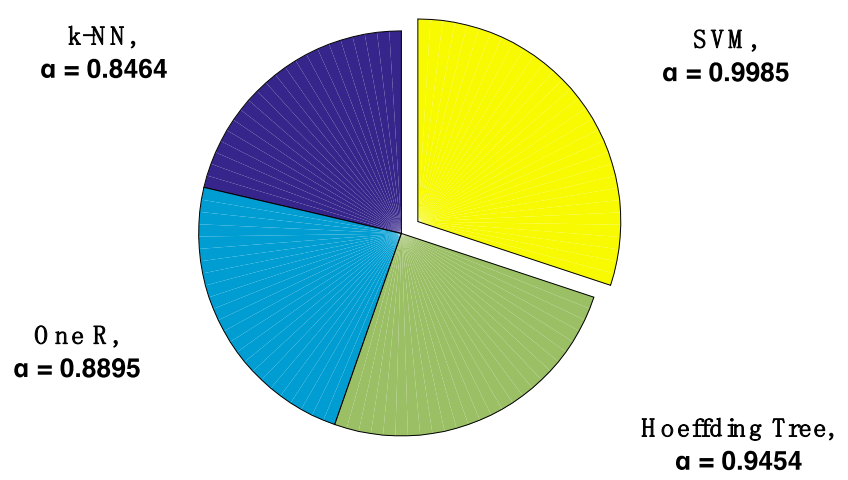

Figure 8. Classifiers prediction accuracy. 


\subsection{Experimented Classifiers Confusion Matrix}

To further assess the efficiency of the adopted classification model authors exploited the confusion matrixes of all the classifiers. As it is shown from Table 4, confusion matrix for the SVM classifier outperformed the prediction results of the other tested classifiers.

Table 4. Confusion matrixes of all the experimented classifiers.

\begin{tabular}{cccccc}
\hline & k-NN & & \multicolumn{3}{c}{ One R } \\
\hline Class 0 & Class 1 & $\leftarrow$ Classified as & Class 0 & Class 1 & $\leftarrow$ Classified as \\
\hline 158 & 73 & class 0 & 164 & 67 & class 0 \\
34 & 432 & class 1 & 10 & 456 & class 1 \\
\hline \multicolumn{3}{c}{ Hoeffding tree } & & \multicolumn{3}{c}{ SVM } \\
\hline 205 & Class 1 & $\leftarrow$ Classified as & Class 0 & Class 1 & $\leftarrow$ Classified as \\
\hline 12 & 26 & class 0 & 231 & 0 & class 0 \\
& 454 & class 1 & 1 & 465 & class 1 \\
\hline
\end{tabular}

\subsection{Experimented Classifiers Time to Build Model}

The time to build model, $t$, was also used as a qualitative evaluation metric to assess the overall efficiency of the experimented classification models with regards to algorithm complexity and computational costs. In Table 5 it is observed the values of $t$ for the selected classifiers. The classifiers of $k-N N$, OneR and Hoeffding tree achieve lower $t$ while SVM achieves the higher $t$. Although it seems that SVM was not as efficient as the other classifiers, this did not hold in our case because we needed to train the selected models only once to get the classification output. In addition, a poor value of $t$-which was in case of SVM-was still exceptionally low, actually less than a single second. Under this assumption, it did not really matter the high value of $t$, but rather the high value of an SVM classifier, which added value in the concept of this study, where training process happened only once.

Table 5. Time to build models of all the experimented classifiers.

\begin{tabular}{cc}
\hline k-NN & One R \\
\hline $0.01 \mathrm{~s}$ & $0.02 \mathrm{~s}$ \\
\hline Hoeffding tree & SVM \\
\hline $0.17 \mathrm{~s}$ & $0.49 \mathrm{~s}$ \\
\hline
\end{tabular}

\subsection{Weka Classifiers Parameter Tuning}

We have discussed that the proposed study is based on classifiers available on Weka machine learning workbench [79]. To support and reproduce our findings, we need to explain the tuning parameters of each classifier. Such tuning includes selected hyperparameters, sampling procedures, computational costs and experimental settings associated to each classification model for training and testing. Actually, in this study the authors used the default tuning parameters available by the graphical user interface (GUI) of Weka workbench for the selected classifiers. This means that the prospective researcher that would like to experiment and reproduce our findings based on certain tuning parameters could use Weka default GUI to run the same experiments with the adopted classifiers and observe the same results. The reason why the authors used the default settings was that Weka proposes such tuning parameters after experimented with several datasets and empirically proposes a set of parameters. However, it holds that machine learning is an empirical science and there is no possibility of someone to propose an overall best practice for a certain type of dataset. What is proposed in practice, is to work with several classification models and choose the best among them for a selected research area, given certain assumptions for the parameter tuning. In our study, we experimented with 
various settings of the parameter tuning for certain training and testing datasets emerged by 10-fold cross-validation evaluation method and we found that the default settings of Weka, for the considered classifiers, had the optimal behavior in the examined study. Thus, we accepted this parameter tuning as the proposed one for the incorporated classifiers.

\section{Discussion}

The proliferation of the Internet, the broadband expansion, the widespread use of mobile and wireless services, and the high-speed communication have emerged cloud computing to ubiquitous technological event [80]. Globalization demands technologically advanced products and services, containing an increased level of knowledge and specialization [44]. Thus, technology driven innovation offers enhanced welfare for stakeholders, public organizations, large-scale enterprises, SMEs and for society [60]. cloud computing adoption resulted in important technological advantages for economic organizations, by improving their productivity, reducing their hardware and software costs while increasing their competitiveness, without affecting the quality of the services provided [81].

In approaching the challenges and the realities to enable organizations to create and profit from innovation, Chesbrough [82] illustrated open innovation in a contemporary business and managerial context. Indeed, modern organizations have achieved tremendous success by linking all activities together in a substantially tight, quick and cheap way of functionality. Subsequently, the cost of starting a new business has fallen substantially due to the ability to use open source software as a building block, while housing storage in a cloud paying for only for what they use [82]. The author denoted that businesses must share their innovation processes. Specifically, businesses should open their knowledge flow to generate new growth, while the unused internal knowledge must flow openly to stakeholders, such as the academia and society. This helps generating new revenue and future business opportunities. Therefore, open innovation will reach the university context since it leads to long-term benefits [82]. Other indicative sectors gaining from open innovation applicability are those of transportation industry, government regulation, public transportation and automotive industry [83].

Technology is a leading force to economic growth while the dynamics of economic life are complex and have a cyclic character. According to the entrepreneurial cyclical dynamics model of open innovation economic dynamics nowadays stems from the synergy of three sub-economies [84]. The synergy of the market open innovation economy based on SME's and startup business, the synergy of the closed open innovation based on large-scale business and finally the synergy of the social open innovation. The balance between the three sub-economies leads to increased economy dynamics and to economic growth [84]. Therefore, academia policy makers should aim for synergies with industry and society.

According to the concept of the quadruple helix model [85], this sets the direction in which open innovation policy makers should move. This model suggests four main players engaged to the application of open innovation: university, government, industry and society. According to this model, the application of open innovation practices promotes the notion of sustainability of the economy, society and environment. Concerning the universities, this can be achieved by focusing on simultaneous combined actions of resources and experience sharing with the industry. More specifically, universities can contribute with scientific research, knowledge and technology transfer. Furthermore, they can act as a trusted third-party. The industry on the other hand, offers the platform for crowdsourcing, the supply chain management and forwards the alliance between large firms and SMEs [85].

Open innovation systems should be carefully designed and implemented to achieve their purposes. Special care should be given to control the cost and the complexity of such systems and reinforce the positive effects of information sharing and outsourcing. As presented for the case of Alibaba platform, the open innovation strategy applied from 1997 to 2017, although it had positive effects and led to an expansion of activities, it also created an increase in cost and complexity to the system [86]. Therefore, in the university context, open innovation policy makers should focus on providing enough 
information feedback loops to open innovation systems and at the same time take actions to strengthen the open innovation culture of the organization.

The main challenges of open innovation are, first, how to execute and govern this new mode, second, to investigate the dynamics and differences of business models and how they interact and work altogether and, third, to determine the intensive relationship developed while focusing on diverse open innovation business models [83]. Therefore, critical issues that are triggered by the application of diverse business models and university policy makers should consider, are the platform trust and the data safety that arise while formulating open innovation platforms [83].

On the other hand, innovation is a risky business that has high failure rates since almost $96 \%$ of all innovations do not return their capital cost, and $66 \%$ of new products fail within two years. Contrarily, there are vast potential benefits of innovation policies prospected. Specifically, innovation policies should recognize that the linear research-and-development model will be outpaced by a nonlinear, open and collaborative innovation process that follows the conceptualization of "fail fast, scale fast" [87]. Indeed, prototypes need to be converted into viable commercial products or services through scaling up the new infrastructure globally [87]. In such a successful case of open innovation functionality to business environments, it is noteworthy the case of the NBI group. Particularly, the NBI group follows a quite selective process, where in a typical year, the team evaluates $50-100$ projects and launches ten to twenty investigations. Then, five to ten of these investigations are seeded as formal projects, with the expectation that one to two of them will go to market. In scaling down the seeding projects by the NBI group the final formalized seed projects are falling in areas of mobility, cloud computing, Internet of Things and Data Analytics [82].

In a similar business environment Curley [87] examined an emerging innovation tool that diffuses among universities, industry, governments and communities by exploiting disruptive technologies-such as cloud computing, the Internet of things and big data-to quickly and effectively solve societal challenges in sustainable and profitable ways, called open innovation 2.0 [87]. This author opened a critical argumentation on involving open innovation into effect at contemporary institutions and companies that remain unaware of this radical managerial shift. Particularly, there is often a confusion between invention and innovation. Invention is the creation of a technology or method, while innovation concerns the use of that technology or method to create value. In addition, institutional or societal cultures can inhibit user and citizen involvement, while intellectual property (IP) models may inhibit collaboration. Other managerial constraints are the fact that governmental funding can stifle the emergence of ideas by requiring that detailed descriptions of proposed work be specified before research can begin, while policymaking may lag behind the marketplace [87].

A research on senior executives in European public sector revealed that digitalization and e-government are important reforming trends, capable of enhancing efficiency and effectiveness of provided services [88]. Greece recently faced an economic and budgetary pressure and still suffers from the impact of its consequences. The demand for modernization of procedures and services may be bridged by digitalization of services through transit to cloud computing usage. Increased adoption of cloud computing can result in enhanced job opportunities, increased technological competence, technological flexibility and competitiveness growth. A study from the Foundation for Economic and Industrial Research [81], supports that Greece can benefit up to $€ 16$ billion by 2021 from a rapid adoption of cloud computing, based on cost saving procedures (by freeing IT costs on installing and maintaining applications locally, on know-how and on saving energy from electricity consumption needed to run and cooling hardware equal, to $€ 4.8$ billion). The secondary effects include the creation of about 38,000 new jobs [20].

Policy makers and managers, within the process of change management procedures, need to focus on the performance gains from the adoption of new technology and analyze the users' willingness to accept and use the cloud computing. In drawing policy-making and strategies regarding the bias among smart cities, the scalability and the humanitarian orientation of smart cities development across the micro, mezzo and macro levels of analysis, it remains challenging to bypass that bias, while finding 
ways in which: (a) cities/urban areas are influencing growth and development strategies and (b) inter and multidisciplinary research is advancing to bridge between the normative and the empirical in the smart cities debate [89]. In the relevant literature a variety of such complementary interdisciplinary perspectives include computing/ICT, political economy, public policy, technology driven innovation and entrepreneurship, are all proven increasingly sophisticated technologies, unveiling the determination of urban computing as a conceptual and methodological framework that integrates the plethora of and their applications in city/urban space. In this way urban computing is perspective to exercise targeted solutions for the challenges that the cities/urban spaces face. In addition, the aforementioned framework should be proven effective to conceive of and build synergies, and to apply in the city/urban space context a wide variation of targeted approaches and techniques [90]. The implementation of scientific bodies aids with advice, can educate users and promote the best practice to provide security assurance in cloud computing. Legal issues concerning privacy and data protection should be applied thoroughly by law makers before a large implementation of cloud computing services in educational establishments. Since "Ease of use" is a significant factor of cloud computing adoption, it should be supported to increase information technology self-efficacy of end users [2]. In addition, educational institutions should be at the edge of implementing new technologies under training programs and open innovation alliances in a cost-effective and environmentally sustainable way [20].

\section{Conclusions}

The main aim of this research was to discover the most appropriate data classification algorithm for the variable of "willingness to use cloud services". The contribution of this study to technology driven innovation through cloud computing in two public universities, Panteion and the University of West Attica, lies in the fact that it has located the main aspects of the users' willingness to adopt such a technology, for the case of these universities. Data were collected from a sample of 697 administrative employees coming from these two Greek universities. The findings of the classification algorithms methods, concerning their appropriateness for the prediction of the "willingness to use cloud computing" variable, indicated that the SVM classifier achieved the highest prediction accuracy compared to the other algorithms (k-NN, One R, Hoeffding tree and support vector machine). The proposed SVM model had a classification accuracy of 0.9985 over the total number of instances. The variable of "easiness to use" was the most important one in determining the users' willingness to use cloud computing.

Descriptive analysis also indicated that university administrative employees strongly agree on the adoption of cloud computing. Though most university employees of our sample reported that they are familiar with cloud computing and use it daily, on the other hand, cloud computing is still not perceived by the respondents as a technology that may increase their job performance or make them work more quickly and effectively. This is happening because the transition to the electronic file and record keeping is currently under development for the Greek public sector and since some documents are kept in their physical form, university employees are spending a great deal of their time dealing with hand-written information. Furthermore, the available computer systems in the university are not enough for all users and they are usually outdated.

Implementation of appropriate support policies such as the strengthening of the e-skills of stakeholders helps in freeing up resources while it enhances and stimulates the concept of open innovation within the university.

\subsection{Implications}

Universities play a significant role in disseminating novelties, new knowledge and promoting research. In Greece, there is still a delay in strategic partnerships between academia and industry for using the universities advantages in open innovation applications. Therefore, university policy makers should consider the importance of the strategic alliances with private companies as they can contribute to the promotion of innovations, such as cloud computing. The industry can also benefit from the 
alliance with the academic partner because it can have reductions in R\&D cost by assigning projects to the academia and using their scientific knowledge [91].

Cloud computing providers need to move towards strengthening the positive attitude of the university users' concerning the "easiness to use" [92]. The gap between users and non-users can be bridged by strengthening the e-skills of the employees that are not familiar with the new technology.

University policymakers should also aim for business information campaigns concerning the benefits of the new technological trend and engage into useful marketing strategies to implement policies of low-cost Internet access. According to Hackbart et al. users perceive a system as easier to use since they gain knowledge and confidence through direct experience [93]. University users also need to experience the reliability and speed of using cloud computing services [94]. The provision of new computers and a low-cost access to high Internet connection speed [95] can strengthen the "easiness to use" aspect of the adoption [20].

Summing up, it is suggested that public university policymakers work on policies that: (a) emphasize and inform the users of the economic and technological advantages of cloud computing such as availability of resources, speed, easiness of use, (b) ensure that the data remains protected by expanding the use of e-signatures and computer security systems, (c) strengthen the e-skills of the users through training and seminars, (d) promote alliances between public and private parties, (e) promote the conversion of paper documents into electronic documents and the expansion of e-signature for the public sector, (f) update and expand the computer availability within the university.

\subsection{Limits and Future Research Topics}

A limitation of the present study is that data concern only two out of the 36 universities in Greece, although the sample covers around $10 \%$ of the total universities' administrative personnel. In addition, the sample participating at the survey was selected by convenience sampling method.

Furthermore, the authors discovered that the proposed methodology of this study on classification algorithms can be applied with particularly good results to determine the most important variables towards users' adoption of cloud services within universities. Future research should be focused in extending the applicable framework to a wider range of Greek universities to cover both urban and rural situated universities and expand the sample size for research verification purposes.

Author Contributions: Conceptualization, E.C.G.; and S.N.; Data curation, T.A.; Investigation, S.N.; Methodology, G.L.K.; Project administration, E.C.G.; Resources, S.N.; Software, T.A.; Supervision, G.L.K.; Validation, T.A.; Visualization, T.A.; and G.L.K..; Writing—original draft, E.C.G..; Writing—review \& editing, E.C.G.; and S.N.; and G.L.K. All authors have read and agreed to the published version of the manuscript.

Funding: This research received no external funding.

Conflicts of Interest: The authors declare no conflict of interest.

\section{References}

1. Kaminska, M.; Smihily, M. Cloud Computing Statistics on the Use by Enterprises, EUROSTAT. Available online: https://ec.europa.eu/eurostat/statistics-explained/index.php/Cloud_computing_-_statistics_on_the_ use_by_enterprises (accessed on 20 December 2019).

2. Sharma, S.K.; Al-Badi, A.H.; Govindaluri, S.M.; Al-Kharusi, M.H. Predicting motivators of cloud computing adoption: A developing country perspective. Comput. Hum. Behav. 2016, 62, 61-69. [CrossRef]

3. Zhang, K. Research of remote access system to the digital resources based on cloud computing. Appl. Mech. Mater. 2014, 543-547, 3606-3609. [CrossRef]

4. Cascio, W.; Montealegre, R. How Technology Is Changing Work and Organizations. Annu. Rev. Organ. Psychol. Organ. Behav. 2016, 3, 349-375. [CrossRef]

5. Tornatzky, L.G.; Fleischer, M. The Processes of Technological Innovation; Lexington Books: Lexington, MA, USA, 1990.

6. Alshamaila, Y.; Papagiannidis, S.; Li, F. Cloud computing adoption by SMEs in the north east of England: A multi-perspective framework. J. Enterp. Inf. Manag. 2013, 26, 250-275. [CrossRef] 
7. Low, C.; Chen, Y.; Wu, M. Understanding the determinants of cloud computing adoption. Ind. Manag. Data Syst. 2011, 111, 1006-1023. [CrossRef]

8. Morgan, L.; Conboy, K. Key factors impacting cloud computing adoption. Computer 2013, 10, 97-99. [CrossRef]

9. Yang, Z.; Sun, J.; Zhang, Y.; Wang, Y. Understanding SaaS adoption from the perspective of organizational users: A tripod readiness model. Comput. Hum. Behav. 2015, 45, 254-264. [CrossRef]

10. Al-Somali, S.A.; Gholami, R.; Clegg, B. An investigation into the acceptance of online banking in Saudi Arabia. Technovation 2009, 292, 130-141. [CrossRef]

11. Davis, F.D. Perceived usefulness, perceived ease of use, and user acceptance of information technology. MIS Q. 1989, 13, 319-340. [CrossRef]

12. Sharma, S.K.; Govindaluri, S.M. Internet banking adoption in India: Structural equation modeling approach. J. Indian Bus. Res. 2014, 62, 155-169. [CrossRef]

13. Chong, A.Y.L. Predicting m-commerce adoption determinants: A neural network approach. Expert Syst. Appl. 2013, 402, 523-530. [CrossRef]

14. Shmueli, G.; Koppius, O. Predictive analytics in information systems research. MIS Q. 2011, 35, 553-572. [CrossRef]

15. Sharma, S.K.; Joshi, A.; Sharma, H. A multi-analytical approach to predict the Facebook usage in higher education. Comput. Hum. Behav. 2016, 55, 340-353. [CrossRef]

16. Mell, P.; Grance, T. Effectively and securely using the cloud computing paradigm. NIST Inf. Technol. Lab. 2009, 2, 304-311.

17. Yeo, S.-S.; Jeong, H.-Y.; Choi, H.-G. Management of cloud computing resources for business, industry, and manufacturing system. Appl. Mech. Mater. 2012, 224, 174-177. [CrossRef]

18. Eurostat, Data for Cloud Computing Services (Online Data Code: Isoc_cicce_use). Available online: http://appsso.eurostat.ec.europa.eu/nui/show.do?dataset=isoc_cicce_use (accessed on 12 January 2020).

19. Hellenic Statistical Authority, Methodology, Quality Management and International Relations Division, Statistical Program Section, Statistical Business Register/2017. Available online: https:/www.statistics.gr/en/ statistics/-/publication/SBR01/- (accessed on 21 April 2020).

20. Sultan, N. Cloud computing for education: A new dawn? Int. J. Inf. Manag. 2010, 30, 109-116. [CrossRef]

21. Erdogmus, H. Cloud computing: Does Nirvana hide behind the Nebula? IEEE Softw. 2009, 262, 4-6. [CrossRef]

22. Gupta, P.; Seetharaman, A.; Raj, R.J. The usage and adoption of cloud computing by small and medium businesses. Int. J. Inf. Manag. 2013, 33, 861-874. [CrossRef]

23. Endo, P.T.; Rodrigues, M.; Gonçalves, G.E. High availability in clouds: Systematic review and research challenges. J. Cloud Comput. 2016, 5. [CrossRef]

24. DeCoufle, B. The impact of cloud computing on schools. Data Cent. J 2009. Available online: http://datacenterjournal.com/content/view/3032/40 (accessed on 31 July 2009).

25. Chinta, R.; Culpan, R. The role of open innovation in business-university R\&D collaborations. In Open Innovation Through Strategic Alliances: Approaches for Product, Technology, and Business Model Creation; Palgrave Macmillan: New York, NY, USA, 2014; pp. 146-166. [CrossRef]

26. Birudavolu, S.; Nag, B.; Wali, O. Open innovation in ICT services for quadruple helix model: The cloud proposition. ACM Int. Conf. Proceeding Ser. 2016. [CrossRef]

27. Mell, P.; Grance, T. The NIST Definition of Cloud Computing. Available online: https://nvlpubs.nist.gov/ nistpubs/Legacy/SP/nistspecialpublication800-145.pdf (accessed on 8 June 2020).

28. Ashtari, S.; Eydgahi, A. Student perceptions of cloud applications effectiveness in higher education. J. Comput. Sci. 2017, 23, 173-180. [CrossRef]

29. Sohaib, O.; Naderpour, M.; Hussain, W.; Martinez, L. Cloud computing model selection for e-commerce enterprises using a new 2-tuple fuzzy linguistic decision-making method. Comput. Ind. Eng. 2019, 132, 47-58. [CrossRef]

30. Poniszewska-Maranda, A.; Matusiak, R.; Kryvinska, N. A real-time service system in the cloud. J. Ambient Intell. Hum. Comput. 2020, 11, 961-977. [CrossRef]

31. Chou, D.C. Cloud computing risk and audit issues. Comput. Stand. Interfaces 2015, 42, 137-142. [CrossRef]

32. Lacity, M.C.; Hirschheim, R. Information Systems Outsourcing; John Wiley \& Son: New York, NY, USA, 1993. 
33. Jugend, D.; Fiorini, P.D.C.; Armellini, F.; Ferrari, A.G. Public support for innovation: A systematic review of the literature and implications for open innovation. Technol. Forecast. Soc. Chang. 2020, 156, 119985. [CrossRef]

34. General Data Protection Regulation (GDPR). Regulation EU 2016/679 of the European Parliament and of the Council of 27 April 2016. Available online: https:/eur-lex.europa.eu/eli/reg/2016/679/oj (accessed on 6 June 2020).

35. Somlo, K.; Sziebig, G. Future role of application of new technologies in small-and medium scale manufacturing systems: Regarding Intelligent and advanced manufacturing systems in northern peripheral area. IEEE Int. Symp. Ind. Electron. 2017, 8001510, 1735-1740. [CrossRef]

36. Behrend, S.T.; Wiebe, N.E.; Jennifer, E.; London, E.J.; Johnson, E.C. Cloud computing adoption and usage in community colleges. Behav. Inf. Technol. 2011, 30, 231-240. [CrossRef]

37. Rauniar, R.; Rawski, G.; Yang, J.; Johnson, B. Technology acceptance model TAM and social media usage: An empirical study on Facebook. J. Enterp. Inf. Manag. 2014, 27, 6-30. [CrossRef]

38. Fishbein, M.; Ajzen, I. Belief, attitude, intention and behavior: An introduction to theory and research. Available online: https://www.researchgate.net/publication/233897090_Belief_attitude_intention_ and_behaviour_An_introduction_to_theory_and_research (accessed on 6 June 2020).

39. Ajzen, I.; Fishbein, M. Understanding Attitudes and Predicting Social Behavior; Prentice-Hall: Englewood Cliffs, NJ, USA, 1980.

40. Al-Fraihat, D.; Joy, M.; Masa'deh, R.; Sinclair, J. Evaluating E-learning systems success: An empirical study. Comput. Hum. Behav. 2020, 102, 67-86. [CrossRef]

41. Abdullah, F; Ward, R. Developing a general extended technology acceptance model for e-learning GETAMEL by analyzing commonly used external factors. Comput. Hum. Behav. 2016, 56, 238-256. [CrossRef]

42. Namahoot Kanokkarn, S.; Laohavichien, T. Assessing the intentions to use internet banking: The role of perceived risk and trust as mediating factors. Int. J. Bank Mark. 2018, 362, 256-276. [CrossRef]

43. Muñoz-Leiva, F.; Climent-Climent, S.; Liébana-Cabanillas, F. Determinants of intention to use the mobile banking apps: An extension of the classic TAM model. Span. J. Mark. ESIC 2017, 211, 25-38. [CrossRef]

44. Gkika, E.C.; Giovanis, A.N. Factors affecting the adoption of new technologies: Empirical investigation in the banking system of a Balkan country. In Proceedings of the 4th International Conference: The Economies of the Balkan and the Eastern European Countries in the Changing World EBEEC, Sofia, Boulgaria, 11-13 May 2012.

45. Al-Emran, M.; Arpaci, I.; Salloum, S.A. An empirical examination of continuous intention to use m-learning: An integrated model. Educ. Inf. Technol. 2020. [CrossRef]

46. Kumar, B.A.; Chand, S.S. Mobile learning adoption: A systematic review. Educ. Inf. Technol. 2019, 241, 471-487. [CrossRef]

47. Sarrab, M.; Al-Shihi, H.; Al-Manthari, B.; Bourdoucen, H. Toward educational requirements model for Mobile learning development and adoption in higher education. TechTrends 2018, 62, 635-646. [CrossRef]

48. Park, S.Y.; Lee, H.D.; Kim, S.Y. South Korean university students' mobile learning acceptance and experience based on the perceived attributes, system quality and resistance. Innov. Educ. Teach. Int. 2018. [CrossRef]

49. Makmor, N.; Aziz Abd, N.; Alam Shah, S. Social Commerce an Extended Technology Acceptance Model: The Mediating Effect of Perceived Ease of Use and Perceived Usefulness. Malays. J. Consum. Fam. Econ. 2019, 22, 119-136.

50. Davis, F.D.; Bagozzi, R.P.; Warshaw, P.R. User acceptance of computer technology: A comparison of two. Manag. Sci. 1989, 35, 982-1002. [CrossRef]

51. Agarwal, R.; Prasad, J. Are individual differences germane to the acceptance of new information technologies? Decis. Sci. 1999, 30, 361-391. [CrossRef]

52. Robey, D. User Attitudes and Management Information System Use. Acad. Manag. J. 1979, 22, 527-538.

53. Venkatesh, V.; Davis, F. A Theoretical Extension of the Technology Acceptance Model: Four Longitudinal Field Studies. Manag. Sci. 2000, 46, 186-204. [CrossRef]

54. Kim, K.J.; Sundar, S.S. Does screen size matter for smartphones? Utilitarian and hedonic effects of screen size on smartphone adoption. Cyberphychology Behav. Soc. Netw. 2014, 17, 466-473. [CrossRef]

55. Kim, H.-W.; Chan, H.-C.; Gupta, S. Value-Based Adoption of Mobile Internet: An Empirical Investigation. Decis. Support Syst. 2007, 43, 111-126. [CrossRef] 
56. Almazroi, A.A.; Shen, H.; Mohammed, F. The Impact of Trust on the Adoption of Cloud Computing Services by University Students. In Recent Trends in Data Science and Soft Computing; Saeed, F., Gazem, N., Mohammed, F., Busalim, A., Eds.; Advances in Intelligent Systems and Computing; IRICT; Springer: Cham, Switzerland, 2018; Volume 843.

57. Sharma, M.; Gupta, R.; Acharya, P. Prioritizing the Critical Factors of Cloud Computing Adoption Using Multi-Criteria Decision-making Techniques. Glob. Bus. Rev. 2017, 211, 142-161. [CrossRef]

58. Venkatesh, V. Determinants of perceived ease of use: Integrating control, intrinsic motivation, and emotion into the technology acceptance model. Inf. Syst. Res. 2000, 11, 342-365. [CrossRef]

59. Lai, P.C. Perceived risk an extension to TAM model: Consumers' intention to use a single platform e-payment. Aust. J. Basic Appl. Sci. 2015, 9, 323-331.

60. Tsamis, A.; Tassopoulos, A.; Gkika, E. Financial institutions as main contributors to society's technology familiarization and adoption of technological trends. In Proceedings of the HSSS 1st International Conference, Tripoli, Greece, 12-14 May 2005.

61. Gangwar, H.; Date, H.; Ramaswamy, R. Understanding determinants of cloud computing adoption using an integrated TAM-TOE model. J. Enterp. Inf. Manag. 2016, 28, 107-130. [CrossRef]

62. Venkatesh, V.; Bala, H. Technology Acceptance Model 3 and a research agenda on interventions. Decis. Sci. 2008, 392, 273-315. [CrossRef]

63. Bandura, A. Self-Efficacy Mechanism in Human Agency. Am. Psychol. 1982, 37, 122-147. [CrossRef]

64. Compeau, D.R.; Higgins, C.A. Computer self-efficacy: Development of a measure and initial test. MIS Q. 1995, 189-211. [CrossRef]

65. Heinssen, R.K.; Glass, C.R.; Knight, L.A. Assessing computer anxiety: Development and validation of the computer anxiety rating scale. Comput. Hum. Behav. 1987, 3, 49-59. [CrossRef]

66. Liao, Z.; Cheung, M.T. Internet-based e-banking and consumer attitudes: An empirical study. Inf. Manag. 2002, 39, 283-295. [CrossRef]

67. Lu, H.-P.; Hsu, H.-P.; Hsu, C.-L. An empirical study of the effect of perceived risk upon intention to use. Inf. Manag. Comput. Secur. 2005, 13, 106-120. [CrossRef]

68. Ma, H.; Hu, Z.; Yang, L.; Song, T. User feature-aware trustworthiness measurement of cloud services via evidence synthesis for potential users. J. Vis. Lang. Comput. 2014, 256, 791-799. [CrossRef]

69. Gkika, E. Tourists' perceptions on satisfaction and sustainable development of tourists' destinations. J. Sustain. Dev. Cult. Tradit. 2017, 1b, 71-82.

70. Goldstein, P. Alternative IT Sourcing Strategies: From the Campus to the Cloud. Available online: https://library.educause.edu/resources/2009/8/alternative-it-sourcing-strategies-from-the-campusto-the-cloud (accessed on 6 June 2020).

71. Rogers, E.M. Diffusion of Innovations, 5th ed.; Free Press: New York, NY, USA, 2003.

72. Davis, F.; Venkatesh, V. A Critical Assessment of Potential Measurement Biases in the Technology Acceptance Model: Three Experiments. Int. J. Hum. Comput. Stud. 1996, 45, 19-45. [CrossRef]

73. Jarvenpaa, S.L.; Tractinsky, N.; Vitale, M. Consumer trust in an internet store. Inf. Technol. Manag. 2000, 1, 45-71. [CrossRef]

74. Tan, M.; Teo, T. Factors Influencing the Adoption of Internet Banking. Int. J. Electron. Commer. $2000,1$. [CrossRef]

75. Nawir, M.; Amir, A.; Lynn, O.B.; Yaakob, N.; Badlishah Ahmad, R. Performances of Machine Learning Algorithms for Binary Classification of Network Anomaly Detection System. J. Phys. Conf. Ser. 2018, 1018, 012015. [CrossRef]

76. Mendez, K.M.; Reinke, S.N.; Broadhurst, D.I. A comparative evaluation of the generalised predictive ability of eight machine learning algorithms across ten clinical metabolomics data sets for binary classification. Metabolomics 2019, 15, 150. [CrossRef] [PubMed]

77. Murugan, N.S.; Devi, G.U. Feature extraction using LR-PCA hybridization on twitter data and classification accuracy using machine learning algorithms. Clust. Comput. 2019, 22, 13965-13974. [CrossRef]

78. Inani, A.; Verma, C.; Jain, S. A machine learning algorithm TSF k-Nn based on automated data classification for securing mobile cloud computing model. In Proceedings of the IEEE 4th International Conference on Computer and Communication Systems, ICCCS 2019, Singapore, 23-25 February 2019; Volume 8821756, pp. 9-13. [CrossRef] 
79. Frank, E.; Hall, M.A.; Witten, I.H. The Weka Workbench. Online Appendix for "Data Mining: Practical Machine Learning Tools and Techniques", 4th ed.; Morgan Kaufmann: Burlington, MA, USA, 2016.

80. Seifu, S.D.; Dahiru, A.A.; Bass, J.M.; Allison, I.K. Cloud-computing: Adoption issues for ethiopian public and private enterprises. Electron. J. Inf. Syst. Dev. Ctries. 2017, 78, 7. [CrossRef]

81. Danchev, S.; Tsakanikas, A.; Ventouris, N. Cloud Computing: A Driver for Greek Economy Competitiveness; Foundation for Economic \& Industrial Research, IOBE: Athens, Greece, 2011.

82. Chesbrough, H. Open Innovation Results: Going Beyond the Hype and Getting Down to Business; Oxford Scholarship: Oxford, UK, 2020; p. 201, ISBN 9780198841906. [CrossRef]

83. Yun, J.J.; Zhao, X.; Wu, J.; Yi, J.C.; Park, K.; Jung, W. Business Model, Open Innovation, and Sustainability in Car Sharing Industry-Comparing Three Economies. Sustainability 2020, 12, 1883. [CrossRef]

84. Yun, J.J.; Won, D.; Park, K. Entrepreneurial cyclical dynamics of open innovation. J. Evol. Econ. 2018, 28, 1151-1174. [CrossRef]

85. Yun, J.J.; Liu, Z. Micro- and Macro-Dynamics of Open Innovation with a Quadruple-Helix Model. Sustainability 2019, 11, 3301. [CrossRef]

86. Yun, J.J.; Zhao, X.; Park, K.; Shi, L. Sustainability Condition of Open Innovation: Dynamic Growth of Alibaba from SME to Large Enterprise. Sustainability 2020, 12, 4379. [CrossRef]

87. Curley, M. Twelve principles for open innovation 2.0: Evolve governance structures, practices and metrics to accelerate innovation in an era of digital connectivity. Nature 2016, 533, 314-316. [CrossRef]

88. Alonso, J.; Escalante, M.; Orue-Echevarria, L. Transformational Cloud Government TCG: Transforming Public Administrations with a Cloud of public services. Procedia Comput. Sci. 2016, 97, 43-52. [CrossRef]

89. Lytras, M.D.; Visvizi, A.; Torres-Ruiz, M.; Damiani, E.; Jin, P. Urban computing and well-being in smart cities: Services, applications, policymaking considerations. IEEE Access Spec. Sect. Editor. 2020, 8, 72340-72346. [CrossRef]

90. Visvizi, A.; Lytras, M.D. Rescaling and refocusing smart cities research: From mega cities to smart villages. Journal of Science and Technology Policy Management. J. Sci. Technol. Policy Manag. 2018, 9, 134-145. [CrossRef]

91. Cândido, A.C.; Sousa, C. Open innovation practices in strategic partnerships of cloud computing providers. J. Technol. Manag. Innov. 2017, 12, 59-67. [CrossRef]

92. Shih, H.-P. An empirical study on predicting user acceptance of e-shopping on the Web. Inf. Manag. 2004, 41, 351-368. [CrossRef]

93. Hackbarth, G.; Groverb, V.; Yic, M.Y. Computer Playfulness and Anxiety: Positive and Negative Mediators of the System Experience Effect on Perceived Ease of Use. Inf. Manag. 2003, 40, 221-232. [CrossRef]

94. Carr, N. The Big Switch: Re-Wiring the World, from Edison to Google; W.W. Norton: New York, NY, USA; London, UK, 2009.

95. Alharthi, A.; Yahya, F.; Walters, R.; Wills, G. An Overview of Cloud Services Adoption Challenges in Higher Education Institutions. Available online: https:/www.researchgate.net/publication/299365475_An_Overview_ of_Cloud_Services_Adoption_Challenges_in_Higher_Education_Institutions (accessed on 7 June 2020).

(C) 2020 by the authors. Licensee MDPI, Basel, Switzerland. This article is an open access article distributed under the terms and conditions of the Creative Commons Attribution (CC BY) license (http://creativecommons.org/licenses/by/4.0/). 